\title{
Supporting Information \\ Influence of the Extrapallial Fluid of Pinctada fucata on the Crystallization of Calcium Carbonate and Shell Biomineralization
}

Jun Xie, Jian Liang, Juan Sun, Jing Gao, Sirui Zhang, Yangjia Liu, Liping Xie, and Rongqing Zhang

Aragonite Formation in Figure SI2. The aragonite was formed by addition of 50 $\mathrm{mM} \mathrm{Mg}{ }^{2+}$ in the saturated calcium bicarbonate solutions and precipitated for $48 \mathrm{~h}$ without any other additives.

Amino Acids Analysis. The protein bands B and f in Figure 1 were incised, digested and analyzed using LTQ Orbitrap Velos mass spectrometer coupled to UltiMate 3000 Rapid Separation nano LC Systems (Thermo Scientific, Waltham, MA, USA). The MS/MS data were analyzed by Mascot 2.1 against the pfu_aug1.0_Pall.fasta.gz database (http://marinegenomics.oist.jp/genomes/gallery). The proteins with score $\geq 5.0$ were selected, merged and the amino acids ratio was analyzed on http://web.expasy.org/protparam/. 
Table SI1. The main elements of Artificial Sea Water and Natural Sea Water

\begin{tabular}{ccc}
\hline Items & $\begin{array}{c}\text { Artificial Sea Water } \\
(\mathrm{S}=35 \%)\end{array}$ & $\begin{array}{c}\text { Natural Sea Water } \\
(\mathrm{S}=35 \%)\end{array}$ \\
\hline $\mathrm{d}\left(\mathrm{t}=24^{\circ} \mathrm{C}\right)$ & $1.024 \sim 1.026$ & 1.025 \\
$\mathrm{pH}$ & $8.1 \sim 8.4$ & $7.8 \sim 8.5$ \\
$\mathrm{KH}$ & $7 \sim 11$ & $7 \sim 9$ \\
$\mathrm{Na}^{+}(\mathrm{mg} / \mathrm{L})$ & $9300 \sim 9700$ & 9370 \\
$\mathrm{Mg}^{2+}(\mathrm{mg} / \mathrm{L})$ & $1300 \sim 1450$ & 1240 \\
$\mathrm{~K}^{+}(\mathrm{mg} / \mathrm{L})$ & $340 \sim 380$ & 326 \\
$\mathrm{Ca}^{2+}(\mathrm{mg} / \mathrm{L})$ & $350 \sim 400$ & 343 \\
$\mathrm{Sr}^{2+}(\mathrm{mg} / \mathrm{L})$ & $8.0 \sim 9.5$ & 6.86 \\
$\mathrm{Rb}^{2+}(\mathrm{mg} / \mathrm{L})$ & $0.10 \sim 0.13$ & 0.1 \\
$\mathrm{Fe}^{(\mathrm{mg} / \mathrm{L})}$ & $0.06 \sim 0.20$ & 0.01 \\
$\mathrm{Li}^{+}(\mathrm{mg} / \mathrm{L})$ & $0.14 \sim 0.16$ & 0.14 \\
$\mathrm{Cl}^{-}(\mathrm{mg} / \mathrm{L})$ & $17000 \sim 17600$ & 17000 \\
$\mathrm{SO}_{4}^{2-}(\mathrm{mg} / \mathrm{L})$ & $2300 \sim 2430$ & 2273 \\
$\mathrm{Br}^{-}(\mathrm{mg} / \mathrm{L})$ & $20 \sim 40$ & 56 \\
$\mathrm{~F}^{-}(\mathrm{mg} / \mathrm{L})$ & $0.7 \sim 0.9$ & 1.1 \\
$\mathrm{~B}(\mathrm{mg} / \mathrm{L})$ & $4.0 \sim 6.0$ & 3.94 \\
\hline
\end{tabular}

Table SI2. The primers used in qPCR

\begin{tabular}{cc}
\hline Primers & Sequence \\
\hline qGAPDH-F & GCCGAGTATGTGGTAGAATC \\
qGAPDH-R & CACTGTTTTCTGGGTAGCTG \\
qACCBP-F & GACATGGAACAAAGATGGTGGA \\
qACCBP-R & CTGTGGCTGGAATGGTTGG \\
qPfN23-F & AGGGTCAAGGTCATCCA \\
qPfN23-R & TAAGCGAGCTTTTCCAA \\
qPif-F & TGCTGCCATCACGTGAGTATG \\
qPif-R & GACTTCCCTTTCTCACACTTCCA \\
qNacrein-F & GAGCCAGAGGATGGGGAAA \\
qNacrein-R & GCCTCCATAGGTGTGAAACGA \\
qKrmp-F & AGAATGAAGTTCGCCGC \\
qKrmp-R & GCATTTCCAATCCCAGG \\
qP39-F & CTGGAATGAGAGGATATG \\
qP39-R & TGCTGCTGTAATAACTATA \\
\hline
\end{tabular}


Table SI3. The amino acids of EPF proteins binding to different crystals.

\begin{tabular}{ccc} 
& PBC & PBA \\
\cline { 2 - 3 } Amino acids & \multicolumn{2}{c}{ \% of the total amino acids } \\
\hline Ala & 6.5 & 6.4 \\
Arg & 4.6 & 5.6 \\
Asn & 5 & 4.3 \\
Asp & 6.3 & 6.1 \\
Cys & 1.9 & 2.3 \\
Gln & 3.7 & 4 \\
Glu & 6.3 & 7.1 \\
Gly & 6.8 & 7 \\
His & 2.2 & 2.7 \\
Ile & 5.9 & 5.7 \\
Leu & 8 & 7.4 \\
Lys & 7.1 & 5.3 \\
Met & 2.8 & 3.1 \\
Phe & 4 & 4 \\
Pro & 4.1 & 4 \\
Ser & 6.8 & 6.5 \\
Thr & 6.1 & 6.8 \\
Trp & 1 & 1 \\
Tyr & 3.8 & 3.8 \\
Val & 6.9 & 6.9 \\
\hline
\end{tabular}

Note: PBC: proteins binding to calcite; PBA: proteins binding to aragonite. 


\section{$\begin{array}{lllllll}1 & 2 & 3 & M & 4 & 5 & 6\end{array}$}

170

70

40

35

25

15

10

Figure SI1. SDS-PAGE of BSA binding to calcite and aragonite: Lanes 1-3, water washings from calcite, $500 \mathrm{mM} \mathrm{NaCl}$ washings from calcite and $1 \mathrm{M}$ acetic acid dissolution from calcite. Lanes 4-6 are the corresponding washings from aragonite. The side numbers are the molecular weights $(\mathrm{kDa})$ of the protein makers $(\mathrm{M})$.

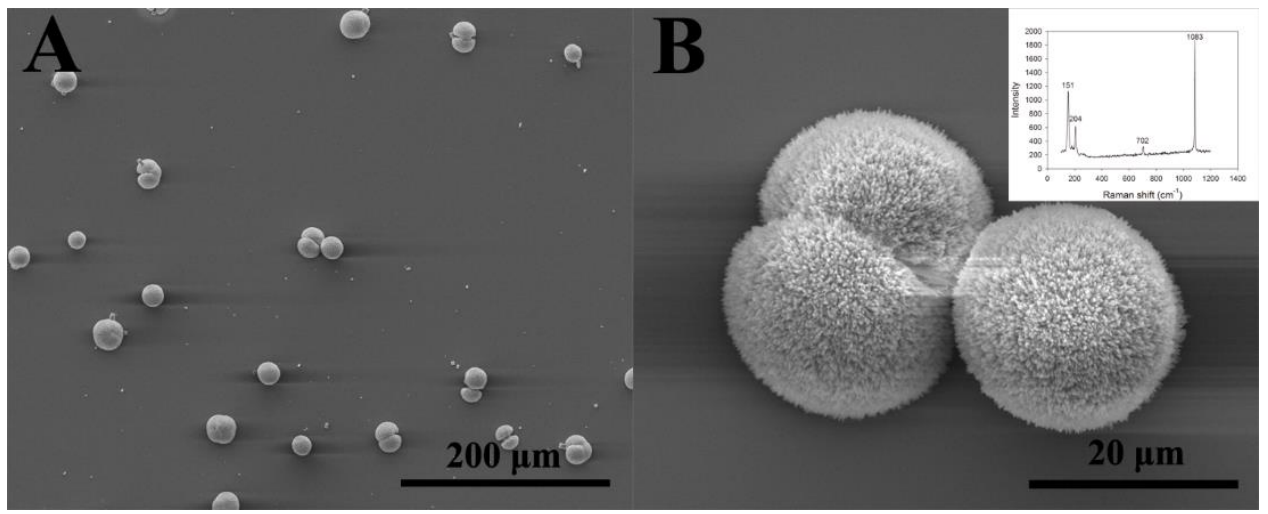

Figure SI2. SEM pictures of aragonite crystals obtained from crystallization experiments in vitro: $\mathrm{B}$ is a magnification of the crystals in A and their Raman spectra. 


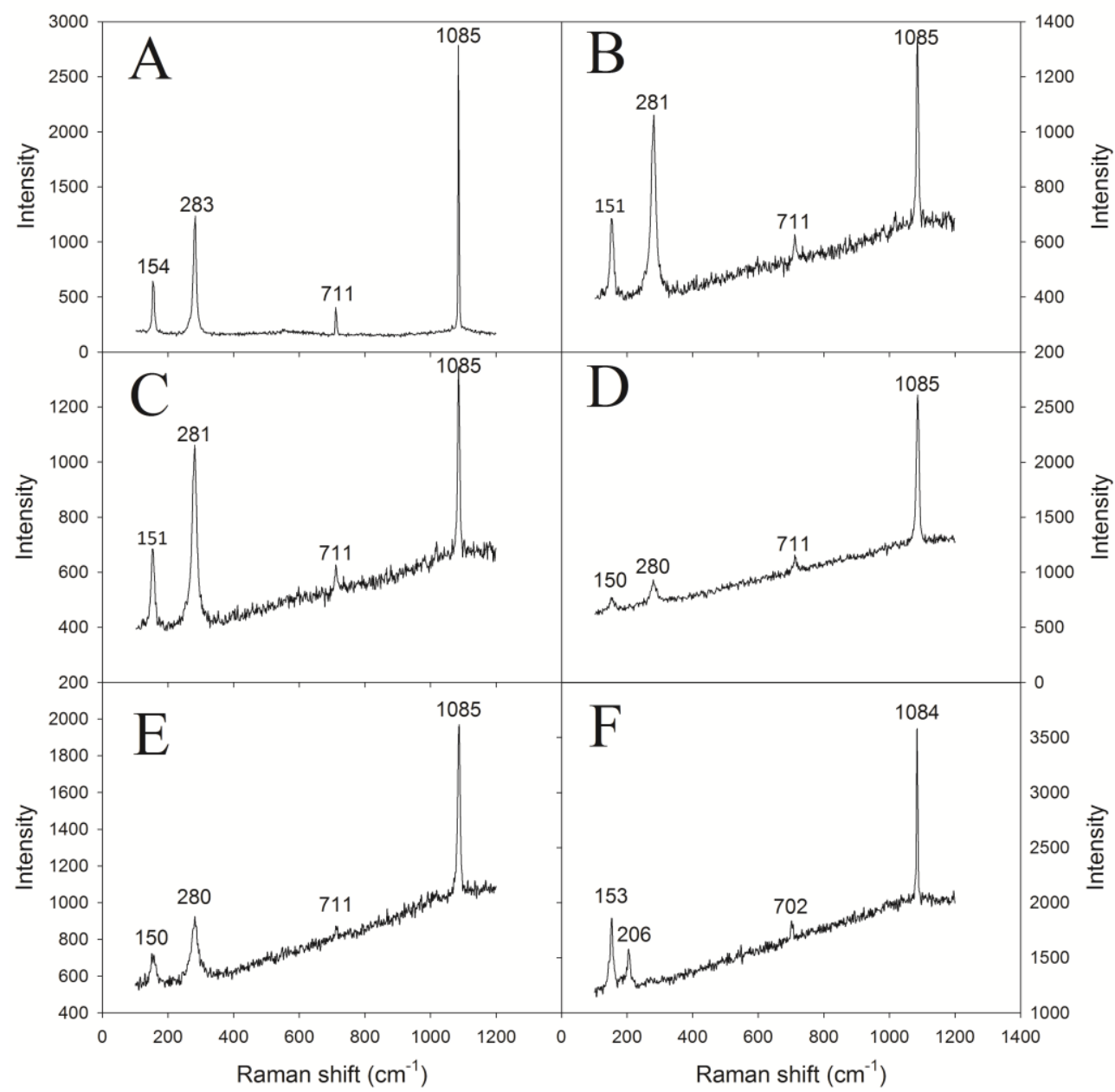

Figure SI3. Raman spectra of $\mathrm{CaCO}_{3}$ crystals obtained from crystallization experiments in the presence of EPF: A-D, Raman spectra of $\mathrm{CaCO}_{3}$ crystals obtained in the presence of ASW, 10, 30, $50 \mu \mathrm{g} / \mathrm{mL}$ EPF. E-F, Raman spectra of $\mathrm{CaCO}_{3}$ crystals obtained in the presence of $30 \mu \mathrm{g} / \mathrm{mLEPF}$ proteins binding to calcite and aragonite, respectively. 

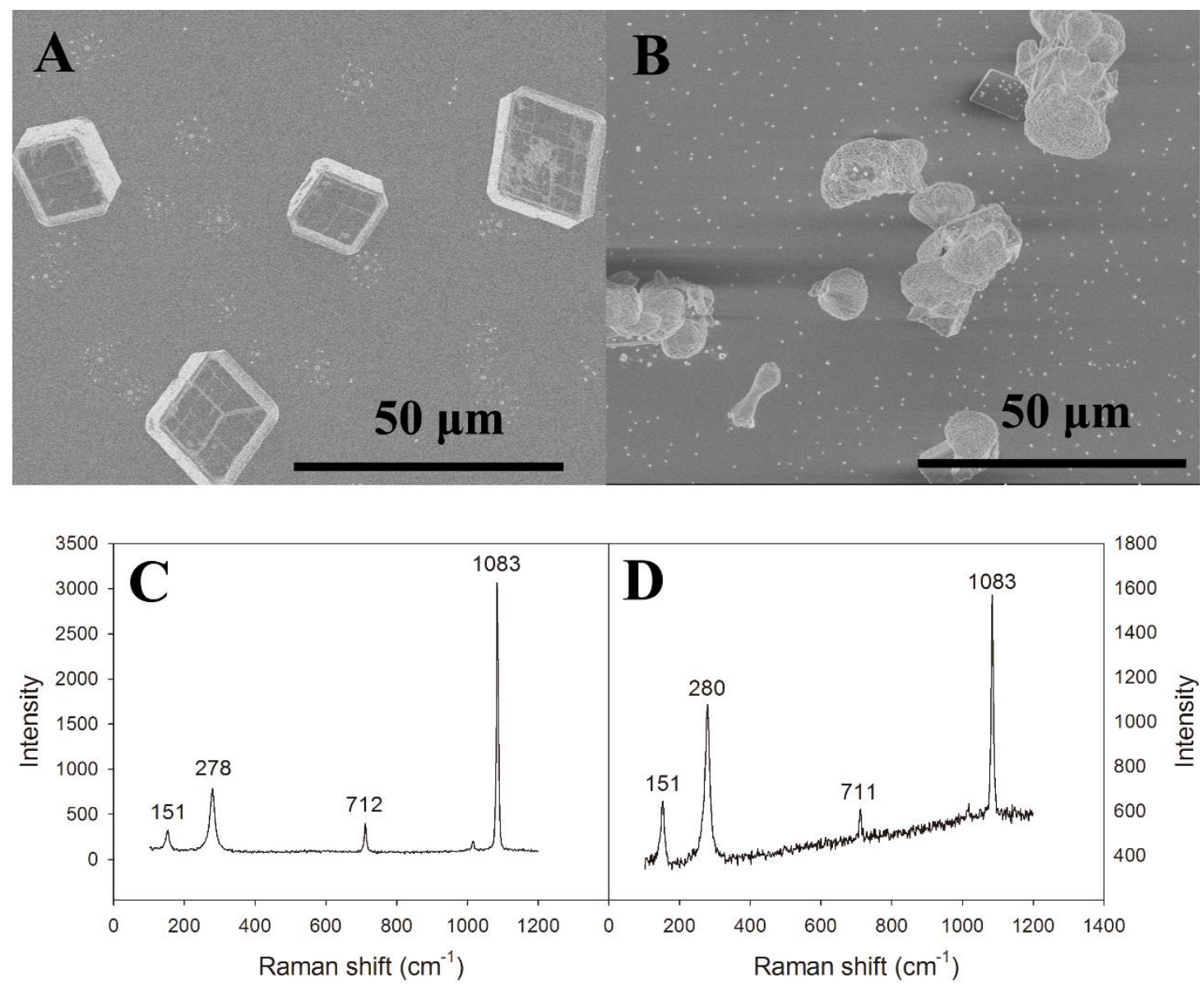

Figure SI4. SEM images of crystals obtained from crystallization experiments on calcite: A, ASW; $\mathrm{B}, 30 \mu \mathrm{g} / \mathrm{mL}$ EPF. C and D, Raman spectra of crystals formed on calcite.

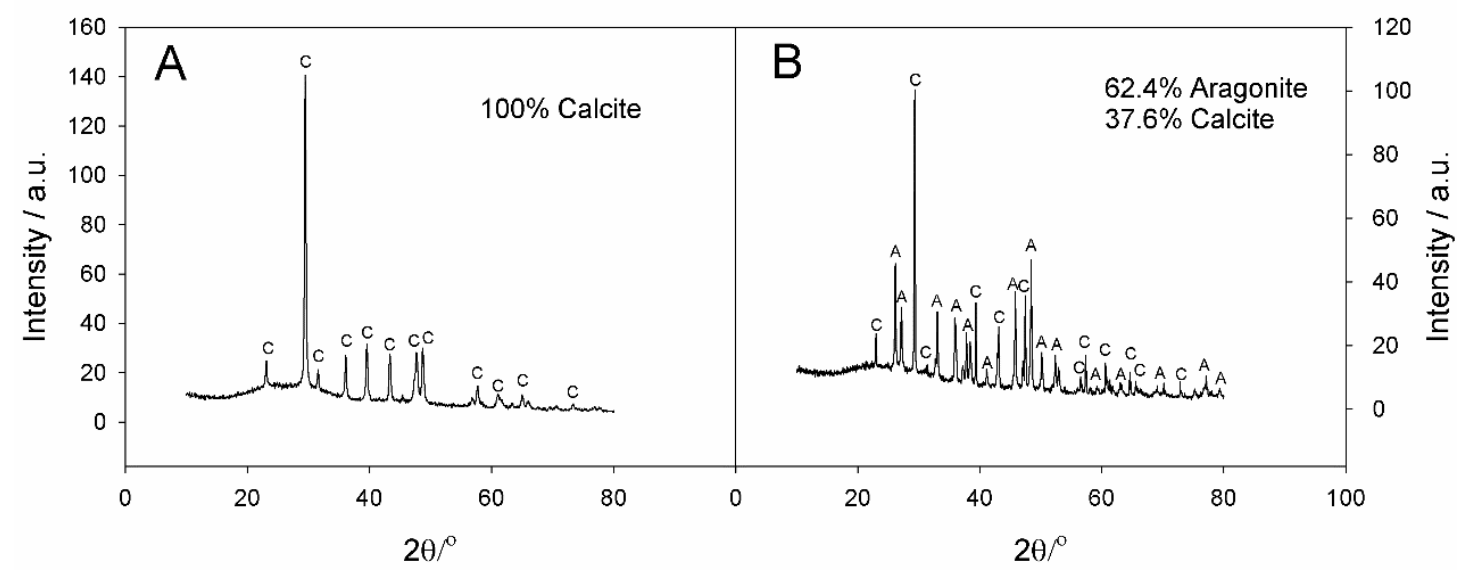

Figure SI5. XRD spectra of crystals obtained from crystallization experiments of EPF proteins binding to calcite (A) and aragonite (B): C: calcite; A: aragonite. 


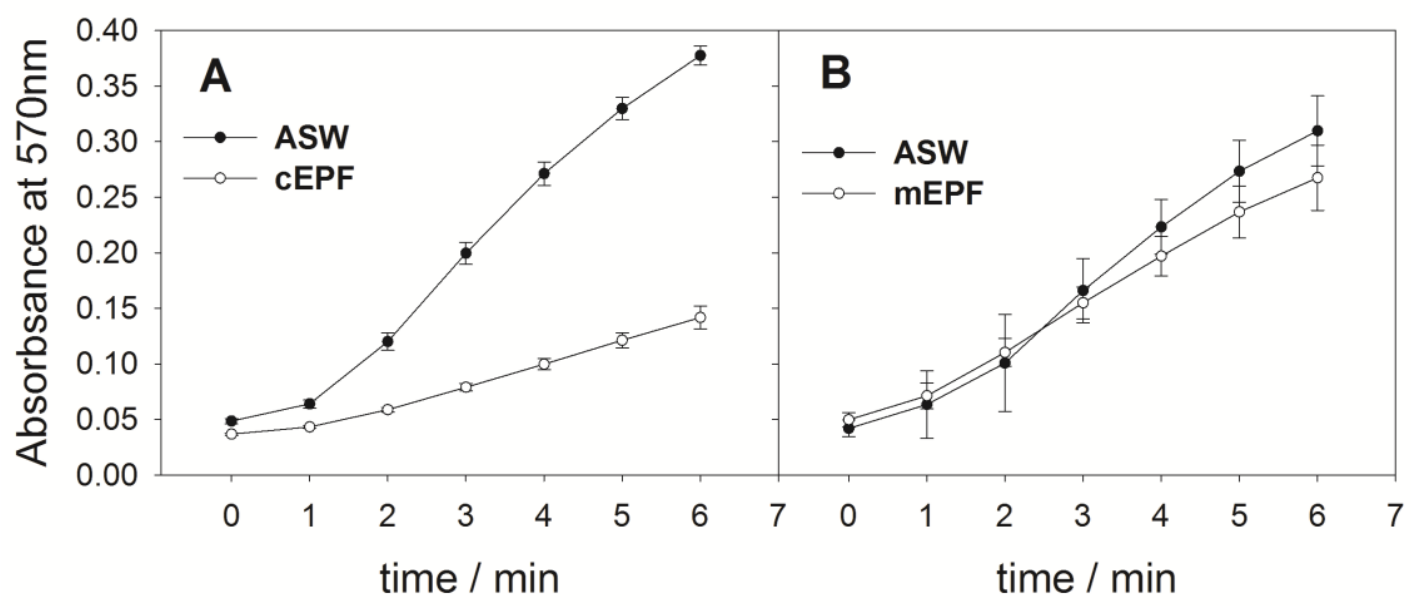

Figure SI6. The precipitation rate of $\mathrm{CaCO}_{3}$ indicated by the crystal absorbance at $570 \mathrm{~nm}: \mathrm{A}, \mathrm{cEPF}$ represented EPF concentrated by a 3-kDa Millipore Amicon Ultra-15 centrifugal filter device (significant difference in the crystallization rate appeared at 1-6 min between the cEPF and ASW $(\mathrm{p}<0.01))$. B, mEPF represented the effluent from a 3-kDa Millipore Amicon Ultra-15 centrifugal filter device (no significant differences in the crystallization rate were observed at 1-6 min between the mEPF and ASW).

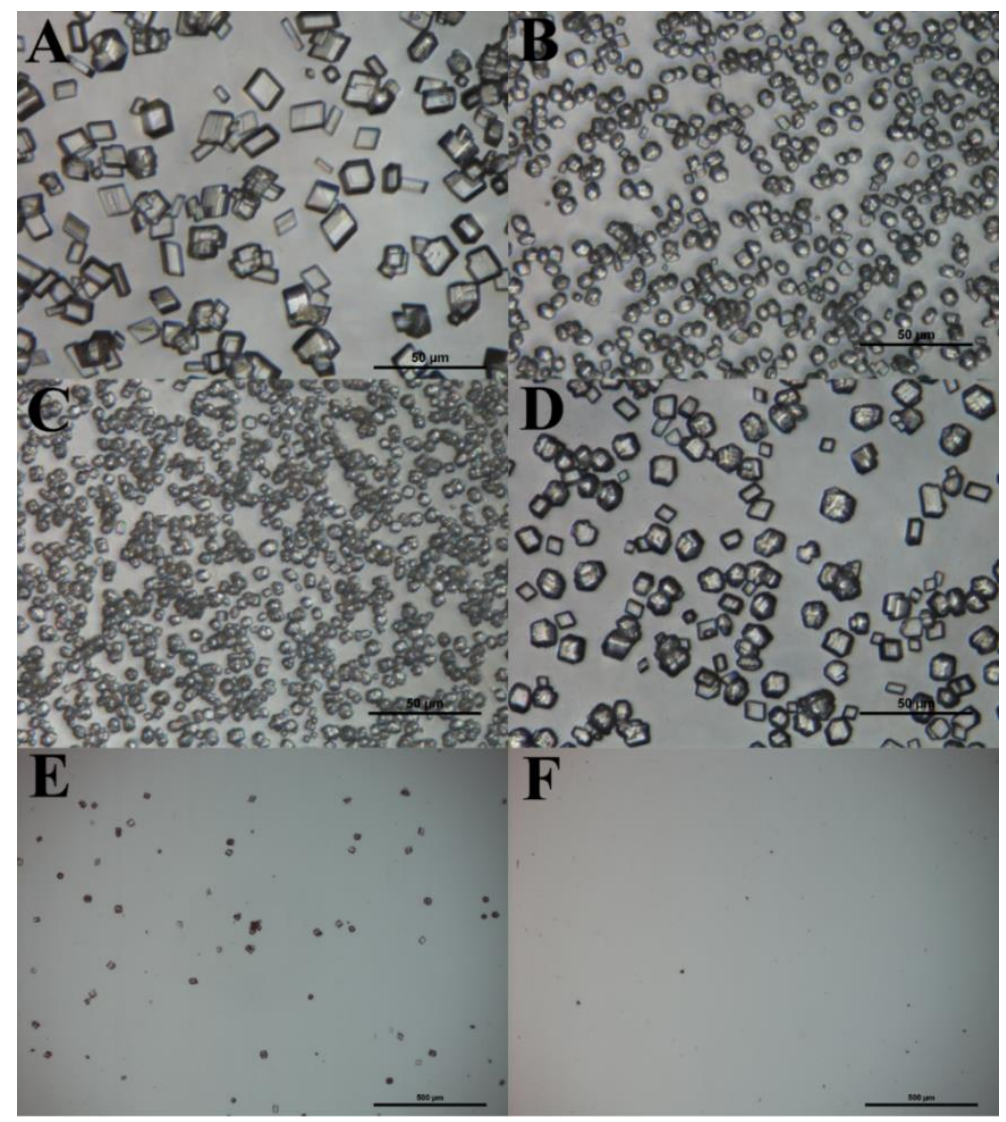

Figure SI7. Optical images of crystals formed in the crystal growth inhibition experiments: Optical images of crystals grown in the presence of ASW (A, E), EPF (B, F), cEPF (C), and mEPF (D). The final concentration of EPF was $50 \mu \mathrm{g} / \mathrm{mL}$, and the same volume of ASW was used in the control. The final concentration of $\mathrm{CaCl}_{2}$ and $\mathrm{NaHCO}_{3}$ was $50 \mathrm{mM}$ in A-D and $5 \mathrm{mM}$ in $\mathrm{E}$ and $\mathrm{F}$. 


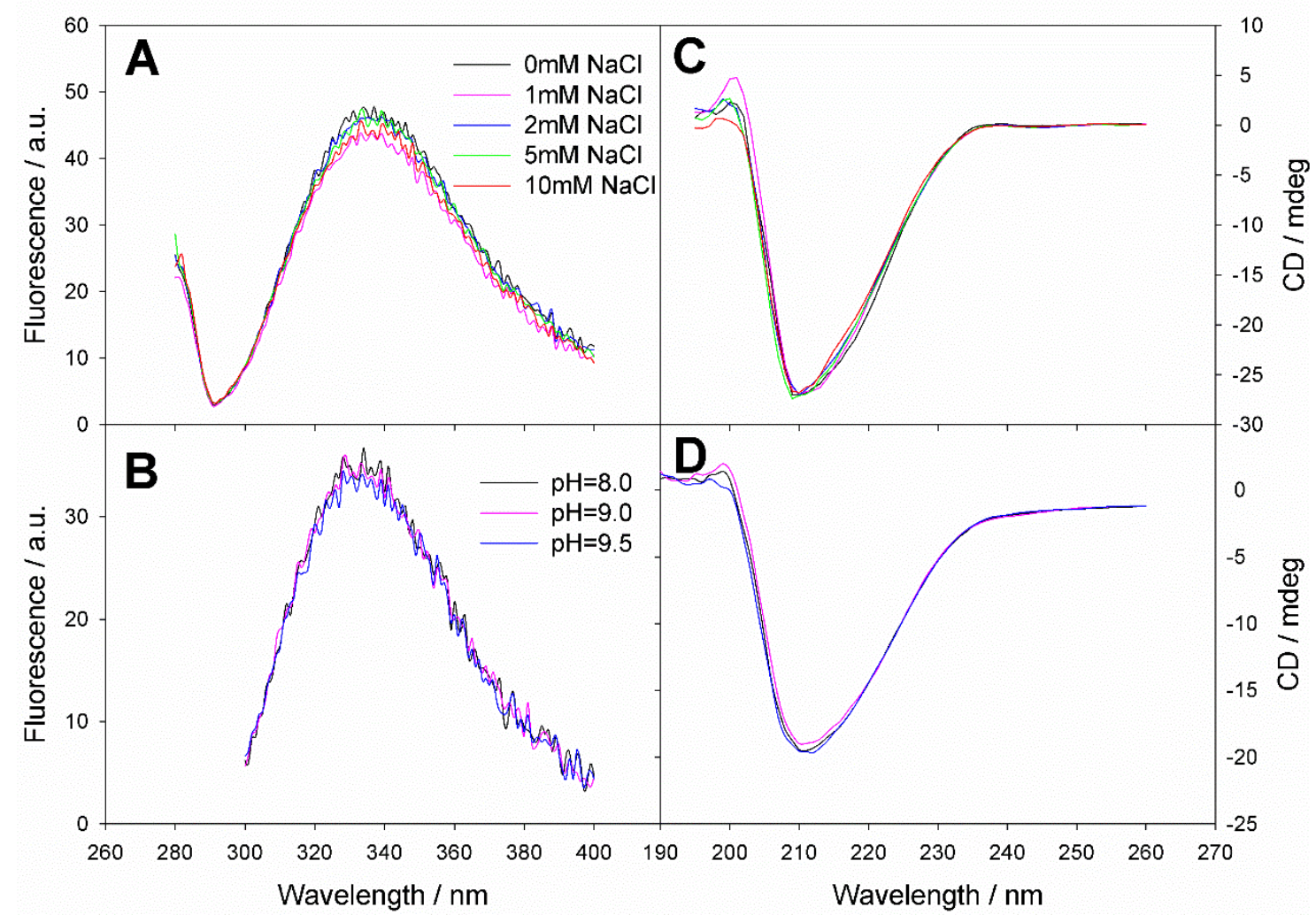

Figure SI8. The intrinsic fluorescence and $\mathrm{CD}$ spectra of EPF proteins in the presence of $\mathrm{NaCl}$ (A, C) and different $\mathrm{pH}$ conditions $(\mathrm{B}, \mathrm{D})$ : the $\mathrm{pH}$ range used in $\mathrm{B}$ and $\mathrm{D}$ represented the variation in our experiments.

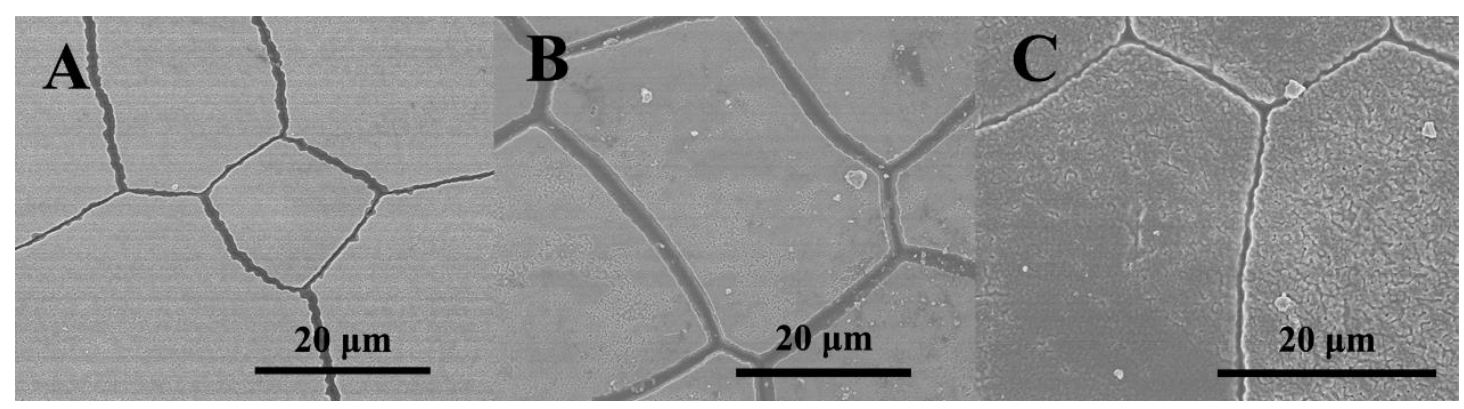

Figure SI9. SEM images of the prism inner face structure upon EPF extraction: A, the inner face of the natural prism of $P$. fucata; B-C, the inner face of the prism after the EPF was extracted for $10 \mathrm{~d}$ and $20 \mathrm{~d}$, respectively. 